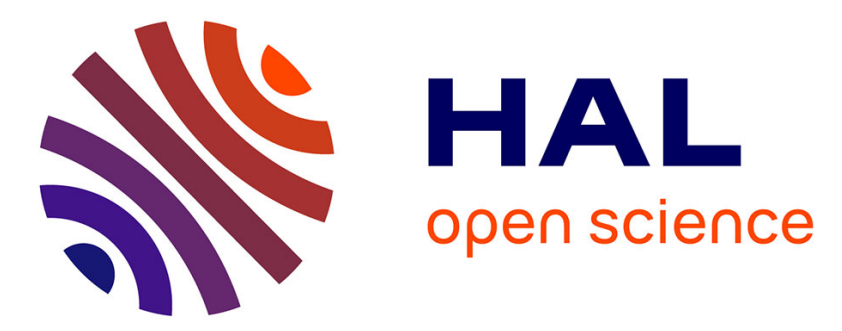

\title{
Collaborative Transformation Systems - Path to Address the Challenges Around the Competitiveness of Mature Countries
}

Americo Azevedo

\section{- To cite this version:}

Americo Azevedo. Collaborative Transformation Systems - Path to Address the Challenges Around the Competitiveness of Mature Countries. 19th Working Conference on Virtual Enterprises (PROVE), Sep 2018, Cardiff, United Kingdom. pp.21-32, 10.1007/978-3-319-99127-6_2 . hal-02191161

\author{
HAL Id: hal-02191161 \\ https://hal.inria.fr/hal-02191161
}

Submitted on 24 Jul 2019

HAL is a multi-disciplinary open access archive for the deposit and dissemination of scientific research documents, whether they are published or not. The documents may come from teaching and research institutions in France or abroad, or from public or private research centers.
L'archive ouverte pluridisciplinaire HAL, est destinée au dépôt et à la diffusion de documents scientifiques de niveau recherche, publiés ou non, émanant des établissements d'enseignement et de recherche français ou étrangers, des laboratoires publics ou privés.

\section{(c)(1)}

Distributed under a Creative Commons Attribution| 4.0 International License 


\title{
Collaborative Transformation Systems - Path to Address the Challenges around the Competitiveness of Mature Countries
}

\author{
Americo Azevedo \\ INESC TEC and Faculty of Engineering, University of Porto, \\ Rua Doutor Roberto Frias, 4200-465 Porto, Portugal \\ ala@fe.up.pt
}

\begin{abstract}
In mature countries manufacturing is one of the most significant sources of economic development and growth. In those countries, manufacturing transformation systems will be grounded on seamless collaborative environments and will have a high degree of flexibility in production, in terms of product needs (specifications, quality, design), volume, timing, resource efficiency and cost, being able to adapt to customer needs and make use of the entire network chain for value creation. Future transformations systems will be massively collaborative and will be enabled by a networkcentric approach, making use of multidimensional data analytics, driven by advanced ICT and the latest available proven manufacturing technologies.
\end{abstract}

Keywords: transformation systems, advanced manufacturing, maturity

\section{Introduction}

We understand transformation system as the combination of assets and processes required to deliver a product (e.g. a manufactured product by a manufacturing industry). By assets we consider the main resources, these include human and capital resources, required for the processing and delivery of goods or services. By processes we consider the set of structured activities, interrelated coherently and forming a network of activities and originating several flows, that transform inputs into outputs and maximizing the value to the different stakeholder's organization.

Mature countries are here understood as established countries with stable, robust and strong economies, advanced capital markets and developed but older infrastructure. Example of such countries include United States, Western Europe, and Japan. Risk factors include aging population, limited economic growth, high national debt, and high pension obligations. These countries seek to continue to be competitive and relevant in today's economy [1].

In the context of transformation systems and mature countries. the importance of advanced manufacturing is being increasingly recognized by policy-makers around the world. The contribution of manufacturing to national economies today is emphasized in national policy documents in terms of delivering well-paid jobs, 
attracting foreign direct investment, increasing productivity and improving other economic variables [2]. In line with this, Europe 2020 strategy underlines the role of 'technology' as the key solution for addressing the challenge of increasing Europe's economic competitiveness and consequently guaranteeing economic growth and job creation. The rationale behind is investing in key enabling technologies, which will help innovative ideas to be transformed "into new products and services that create growth, high-skilled adding-value jobs, and help address European and global societal challenges". In fact, manufacturing is considered a key enabler for Europe's grand societal challenges [3].

Nowadays, in a globalized and increasingly complex world, it is fully recognized that manufacturing industries are under a strong competitive pressure. A proper balance between new collaborative manufacturing strategies, comprehensive organization, management, optimization tools, and cost-efficient automation will provide the basis for building a strong competitive position in the global market. Furthermore, there is a consensual need to create and implement development strategies that can ensure, in a competitive and sustainable way, a growing economy aligned for job creation and solving societal challenges.

In fact, and looking for European Union, the European Council set the objective of making the EU "the most competitive and dynamic knowledge-based economy in the world, capable of sustainable economic growth with more and better jobs and greater social cohesion". It is consensual that is essential to develop a knowledge based industrial system, integrating collaborative dynamic networks of different entities and hiring the competences required to manufacture and deliver custom made products with a time to market able to answer properly to an ever-changing global customer demand. Recognizing the crucial role of industry in the recovery and development of the European economy, a number of European and national programs and initiatives have been launched in recent years around so-called Factories of the Future and Industry 4.0. In this context of change and technological development, the competitiveness of the national industries goes through the modernization of their transformation systems. These should be flexible in adapting to change, responsive to the satisfaction of variable and diversified demand profiles, and efficient both in terms of energy and material consumption and in the use of productive resources. On the other hand, the adoption of collaborative solutions by companies, ensuring greater interaction and integration upstream and downstream, will allow the creation of dynamic and digitally integrated value chains with global efficiency gains.

Manufacturing industries are rapidly adopting a new customer-focused manufacturing paradigm in order to deal with the increasing demand for personalized products. The adjustment from low product variety and high production volume to high mix and low volume poses many important challenges.

Considering the above, we intend in this paper to discuss most relevant critical issues and challenges that we consider crucial in future transformation systems, namely, in advanced high-value manufacturing business environments.

The remaining of the paper is organized as follows: section 2 presents the main critical issues to address in manufacturing transformation systems. Section 3 delves on highlighting key enabling technologies supporting technological solutions for flexibility. Section 4 is about decision support systems in dynamic environments and section 5 highlights key point concerning organization and operations strategies. 
Section 6 raises the idea of promoting the adoption of a technology roadmap strategy, and the paper ends in section 7, with final remarks.

\section{Critical Issues to Address in Manufacturing Transformation Systems}

Nowadays, manufacturing transformation systems are adopting a new paradigm: from low variety and volume-oriented environments (mass production) to high variety and on-demand personalized, customer-driven and knowledge-based production. Furthermore, advanced manufacturing leads to an increasingly automated world that will continue to rely less on labor-intensive processes and more on evolutive information-technology and adaptive intensive processes that enable flexibility. Moreover, advanced manufacturing will become increasingly linked at global level as automation and digital supply-chain management become the backbone across enterprise systems. This new value creation environment is an encouraging approach to significantly improve the competitiveness of the manufacturing industry. Manufacturing, as the core of growth and development of mature economies, must become increasingly high added value, competitive and sustainable, by building on competences and knowledge coming from higher education and R\&D [4].

Delivering high value-added customized products, assessing the performance of the manufacturing systems, managing the operational complexity induced by the product variety, and dealing with different levels of decisions from strategic to tactical and operational, taking into account the impact of disturbances and unplanned events over the plan execution, are issues of great practical relevance that still need to be solved. In that context, it is relevant to address different critical issues, namely:

- To develop new methodological tools and reference models to support the improvement of visibility of collaborative value chains networks, and to anticipate the risks and opportunities of production networks models and of flexible manufacturing strategies.

- To contribute to the enrichment of state-of-art of Digital Factory and Digital Manufacturing (Virtual Manufacturing) through the integration of prediction modelling approaches oriented to the quantifying of the impact of operational decisions in the future system's performance.

- To leverage the decision-making processes in the specific case of high mix and low volume production. To attain such goal, optimisation tools to determine optimized factory designs concerning the utilization of the resources and energy consumption, while enhancing the role of human capabilities in the manufacturing systems will be developed.

- To enhance existing knowledge regarding the performance of Product Service Systems (servitization of manufacturing), throughout the development of an analytical framework that incorporates lifecycle assessment and cost modelling methodologies.

- To contribute to a better understanding of the complex modelling issues that appears when different models and methods, either quantitative or 
qualitative, are combined to solve problems within the transformation systems.

- To contribute to the advancement of the Internet of Things (IoT) in the context of Collaborative Transformation Systems which emphasizes the idea of consistent digitization and linking of all value-chain's resources in an economy. In fact, in our view the merging of the virtual and the physical worlds through cyber-physical systems (which provide the basis for the creation of an IoT in manufacturing) and through enhanced multimedia approaches and the resulting fusion of technical processes and business processes are leading the way to a new industrial age where production processes are fine-tuned, adjusted or set up differently in real time.

- To promote the sustainability and competitiveness of collaborative manufacturing transformation systems. Organizational strategies and tools for advanced manufacturing management systems are crucial objects of research and application for reengineering the future economic tissue of goods and services: i) Efficient and reliable collaborative transformation systems: "address sustainability, integrating the full social, environmental and economic costs and benefits at local, regional and national levels. The quality, reliability and maintainability of products should be incorporated in the development phase and assured during the production process"; ii) Flexible Industries: "Manufacturing industries worldwide are experiencing increasing demands of higher product complexity and diversity from their markets, which require continuous and dynamic change of product design tools, production planning and control approaches, supply chain strategies, logistics and total quality management practices".

- To develop models and methods which can support the design of sustainable high-value chains collaborative networks and innovative strategies in order to face increasing dynamic supply and deliver requirements, increasing pressure for cost optimization and total quality management and business excellence approaches implementation.

Digital value chains

It is recognized around the globe that effective use of digital technologies is key to competitiveness in the modern world. In fact, Collaborative Transformation Systems use massively ICT along with intelligent software applications to optimize the use of material, labor, and energy to produce customized, high-quality products for on-time delivery, and to quickly respond to changes in market demands and supply chains.

Mastery of digital technologies and platforms in high-value chains across all industry sectors - and the consequent "ability to create a digital thread that connects all operations involved in producing goods and services - offers very significant opportunities to create value for the customer and to strengthen the competitiveness of organizations".

The change associated with this digitization of industry is driven by the convergence of three key technological trends related to:

- Connecting "things" to the digital space (driven by IoT - embedded software, sensors, actuators, connectivity, low power ICT etc.); 
- Creating value from knowledge (driven by (Big) Data Science, HPC, cloud computing etc.);

- Deploying autonomous systems (driven by robotics, automation, machine learning, etc.).

The above technologies form the core of an emerging, information-centric, Collaborative Transformation System that "maximizes the flow and re-use of data throughout the enterprise. The ability of disparate systems, however, to exchange, understand, and exploit product, production, and business data rests critically on information standards" [5]. The role of standards will be unavoidable for enabling collaborative transformation systems.

\section{Human-centred Manufacturing}

A key strategic priority is to consider Human capital as the most valuable resource of the collaborative transformation systems, namely considering high added-value manufacturing environments. Thus, future transformation systems will consider the human in focus, being more supportive and friendly to the human operator. Within manufacturing enterprises, the human-centred workplaces, where the technical equipment and tools support the humans, make their job attractive and eventually improve their performance, will enable the employee's full talent and capability to be unfolded. Additionally, even if older skilled jobs may disappear during the envisioned manufacturing renaissance, human-centred manufacturing will create new positions and promote wider inclusion of people to be employed in manufacturing, considering the actual societal challenges, such as ageing workforce. Special focus will be given in making manufacturing more attractive, featuring the harmonisation of the job's quality with operator's satisfaction and commitment.

\section{Knowledge-based Manufacturing}

The quality and availability of a highly skilled workforce and its ability to lead innovation constitute the most important factor for manufacturing competitiveness. Skill gaps and shortages hinder the industry's innovation performance world-wide. On top of that, the employment pattern in the manufacturing industry is changing towards more knowledge - and skills - intensive jobs. New education and training approaches for developing skills and building competences are required.

Taking into account this strategic priority, collaborative transformation systems will focus on the human employee and provide him/her with novel educational/training platforms to build competences for efficiently utilizing the latest, advanced manufacturing equipment. Introducing emerging paradigms for the seamless integration of manufacturing research, innovation, education and training activities, such as the Teaching and Learning Factory paradigms, provide brand new approaches to enrich manufacturing knowledge. Technology-enabled (e.g. ICTs, high-grade industrial didactic equipment etc.), real-life and life-long learning "environments" for building competence and catalysing product and process innovation (for blue and white-collar workers / employees) will be employed.

Teaching and Learning Factories will be real factories in which trainees can learn by using innovative machines, simulate manufacturing tasks and situations, and perform innovation tasks in a real industrial environment bringing training and education closer to industrial needs. The dual approach to knowledge transfer, the 
factory in the classroom and the classroom in the factory, assure both initial and continuous skill improvement of human capital. New business models, emerging with new knowledge transfer technologies, will lead to job creation and economic growth in the education / training business as well.

\section{Sustainable Manufacturing}

A key point in competitiveness is how a firm intends to create and sustain value without compromising the ability of the future generations to meet their own needs. Thus, leading resource efficiency will be a decisive competitive factor for manufacturing, also contributing to the people's wellbeing around factories. In that context, Circular Economy is expected to constitute an extraordinary strategic opportunity for mature countries, also in terms of jobs creation and economic growth since new profitable products and business models can be established by manufacturing companies founded to take care of End-of-Life processes.

Circular economy in manufacturing transformation systems, defining practices that allow to maximise value from products and materials and to minimise the environmental impact via re-using, remanufacturing and recycling, will allow manufacturing to become more competitive and, at the same time, to harmonically coexist with healthy living areas, respecting the landscape and preserving natural resources. Therefore, mature countries can become the leading of the integrated manufacturing/de-manufacturing industrial technologies and also contributing to a global sustainable growth.

\section{Technological Solutions for Flexibility - Key Enabling Technologies}

The competitiveness of transformation systems depends largely on their productivity, flexibility and responsiveness to market demands. Advances in production technologies, such as robotics and collaborative technologies, will play a very important role in the future of the industry. However, their impact on decision support systems is an open question.

One of the main goals in the coming years is the integrated development of advanced robotics with the decision-making process methodologies to increase the productivity of the factories of the future. In the near future the robots will be able to cooperate with humans at their workstation and will receive the production orders in a highly flexible manufacturing scenario. In this way, the best of each partner, robot and human, is exploited, on the one hand, the cognitive abilities and human dexterity that can be concentrated in tasks that add added value to the product and, on the other, the capacity of the robot in performing repetitive tasks accurately.

Continuing this vision in terms of impact on industry requires not only the obvious technological development in terms of robotics but also an integrated development of decision support techniques and tools so that they can incorporate highly flexible production technologies capable to adapt to different tasks with a minimum of reprogramming, with high capacities of perception and of work in environments more designed for human use. This new paradigm represents a challenge for the modelling techniques of production processes where machines / robots are traditionally static 
and flexibility was only guaranteed by human operators. It is thus fundamental to integrate the technological, organizational and social components, developing humancentred automation systems that allow to define the level of optimal automation, guaranteeing efficiency and quality in the work for the operators.

The expected impact through this new approach is reflected in the social, economic and scientific dimensions. The social and economic impact will result from the appreciation of industrial activity, increased productivity, greater flexibility and better working conditions. At the scientific level, a high impact is expected from the innovative approach that investigates robotic and automation technology in combination with management and decision-making processes. Thus, the integrated development of decision tools aligned with the efficient use of advanced production technologies will have to meet the recent challenges of custom and low volume production. To take advantage of the potential of advanced robotics in these scenarios requires a flexible management system that can make real-time decisions and be integrated into an adaptive production system.

\section{Decision Support Systems in Dynamic Environments}

As mentioned, the recent emergence of disruptive technologies may revolutionize advanced production systems in all types of industries, particularly those with high mix and customization, as long as they are accompanied by general management practices and analytical tools that adjust to this new reality.

Transformation activities are typically characterized by high levels of variability (for example, operating income, quantities ordered, variety, delivery dates, demand, etc.) and disturbances (such as equipment breakdowns). These uncertainties trigger a significant deviation between production and maintenance programs and their implementation. Consequently, it is critical that in these dynamic environments the production scheduling and maintenance and maintenance procedures are both proactive and reactive. Dealing with uncertainty poses a significant challenge, especially since the problems of resource scaling and maintenance policy optimization, even when treated without uncertainty (i.e., deterministically) are already intractable. It should be noted that new technologies require greater sophistication in handling scheduling and production control issues, and maintenance management. Thus, it is imperative to define intelligent ways of modelling and solving the complex systems that emerge from this reality. A proactive approach deals with uncertainty in order to produce robust (production or maintenance) programs that can accommodate variability and disturbances. In turn, the reactive approach should promote a rescheduling or a set of real-time maintenance actions that respond in the most effective (and timely) way possible to the uncertainties of the productive environment.

The agile and real-time decision-making process, in addition to incorporating conditions and constraints generated by the use of technology (e.g., robotics), should be supported by a number of advanced analytical methods that promote system 
efficiency, flexibility and agility adaptive production. These methods have different objectives and are employed in different environments, promoting:

- Better information - building on large datasets to get a clear picture of the past / present (identifying patterns and trends);

- Better forecasting - obtaining predictions / careful simulations of events / results and risk estimates to illuminate management challenges at the level of advanced production systems;

- Better decision - supporting complex decisions to improve performance in multiple industries and domains.

These three objectives relate to different types of analytical methods that are not mutually exclusive, but rather collectively exhaustive, namely methods of descriptive analytics, predictive analytics, and prescriptive analytics.

Descriptive analytics uses business intelligence and data mining. Performance data from production schedules can be exploited to provide information on current or past trends of events, revealing details and previous performance. In addition, the treatment and statistical analysis of overall equipment efficiency (OEE) data may reveal factors that are impacting the different types of losses (associated with availability, performance and quality)

Predictive analytics uses a set of algorithms and modelling techniques (such as prediction and simulation) to understand future trends in data. It helps managers anticipate likely scenarios, enabling better informed planning and decision making. However, it does not recommend actions. Exemplifying its role in the case of predictive maintenance, when monitoring and predicting / determining the condition of the machine / production equipment in service, allows to anticipate where and when the failures will occur, as well as the respective causes. Real-time access to multiple sources of information to monitor the condition of the equipment, combined with predictive analytical techniques, allows us to estimate the evolution of asset reliability and take appropriate actions to avoid the consequences of the failure.

Finally, the prescriptive analytics allows to generate optimized and intelligent recommendations and to estimate the future results of decisions, based on descriptive and predictive analyses of structured and unstructured data. Together with risk matrices, cost indicators and estimates of equipment condition evolution, maintenance policies are optimized, maximizing asset availability and improving product quality, leading to increased operating income at an appropriate cost.

Of course, the analytical maturity of industrial firms varies considerably with respect to an organization's ability to use advanced analytical data and methods to support key decision-making processes in the planning of its operations. Companies are trying to progress from the world of descriptive analytics to predictive analytics, and from this to prescriptive. New technological opportunities will accelerate the readiness for this movement.

\section{Organization and Operational Strategy}

The adoption of technologies and solutions that allow in dynamic environments the necessary adaptability and real-time decision making, must be accompanied by 
organizational models and operational strategies oriented to the operational excellence of the value chain. The challenge is to design organizational and management models that promote the alignment of the operational strategy, involving the entire chain, namely its resources and processes, with the organization's own competitive strategy.

In this context there are some key issues, such as:

- How to formulate and evaluate the transformation system, in a logic of value maximization and alignment with the organization's competitive strategy?

- How to choose and adapt the resources and processes that best guarantee the organization's competitive priorities?

- How to sustainably improve operational performance toward excellence?

- How to organize and manage the dynamics of change in a short and mediumterm horizon?

The answer to these questions is not self-evident. In fact, it is very difficult to predict the effects that the decisions and actions taken on the set of resources and processes will have on the future performance of the production system, and on the skills that can guarantee cost, quality, response and flexibility. This is due not only to the technological complexity of the production systems themselves, but to the fact that increasingly environments are characterized by increasingly complex products, low volume and high variety, and demand variability.

The existence of trade-offs and restrictions in the operations system implies that no operational decision can be universally appropriate; instead, each operational strategy implies a "tailor-made" organization and operating system: its resources and processes are configured so that the competencies they generate best fit the customer value proposition specified by the company's competitive strategy. Thus, strategy decisions imply choices in operational competencies.

As environments, competitive strategy, and operations evolve, organizations must strive to maintain the necessary alignment over time. In order to meet a new customer need, the company may need to develop new skills as well as develop and implement new capabilities and processes that may lead to the creation of new products, services and markets. This "dynamic alignment" assumes a continuous process of adaptation to ensure that operations and competitive strategy remain aligned over time.

\section{The Importance of a Technology Strategic Roadmap}

The changes brought about by the digital revolution in the process of transformation and creation of value are radical and represent a real challenge for companies [6]. The digital transformation of current enterprises, namely through Industry 4.0 initiatives, promises to revolutionize their transformation systems, namely concerning reducing costs and expanding business opportunities.

A number of macroeconomic effects and operational benefits are announced. Increasing productivity in more flexible environments, reducing time-to-market, reducing resource unavailability and non-quality are just a few of the gains that are expected to be guaranteed. In addition, in a job creation and destruction balance sheet, it is expected that when maturity is achieved (a period of 10-15 years is expected for 
industry 4.0 to reach maturity). Other benefits include the creation of new value creation networks and the exploitation of new business models, which in turn will lead to new professions. With regard to the envisioned Fourth Industrial Revolution (industry 4.0), "we understand maturity of an industrial enterprise as the state of advancement of internal and external conditions that support Industry 4.0's concepts and fundamentals" [7].

Digital transformation is not just about advanced machines and robotics, smart products and Internet of Things. The use of new technologies and the acquisition of new knowledge, through the selective treatment of information, will inevitably lead to new types and ways of working. The ability to analyze the prevailing organizational culture and the existing patterns of operation will therefore be fundamental to the successful implementation of a Digital Transformation Strategy.

Therefore, within a framework evolving around the principles and concepts of Industry 4.0, the main challenges for companies include understanding what Digital Transformation actually means. A structured approach is a key point. One of the first actions is to evaluate the maturity (digital readiness) of manufacturing companies. Assessing maturity means to conceptualize and measure maturity of an organization regarding some specific target state [8][9]. It is particularly important to define a vision in this context and necessarily aligned with the overall strategy of the company. Identifying priorities and targets to be tackled in the coming years and developing pilot projects (proof of concept) will be the next steps.

Industry 4.0 will have a significant benefit for companies that internalize well what the Fourth Industrial Revolution means and, in particular, how they can operate and develop their business, in a logic of looking at the entire value chain, that is, far beyond the traditional frontier of the company. Moreover, collaborative networks $[10,12,13]$ will have a key role in enabling future industrial's competitiveness. As stated by Camarinha-Matos et. al. [11], "collaboration is at the heart of most challenges in Industry 4.0 and thus the area of Collaborative Networks shall be considered as an enabler - although certainly not the only one - for this industrial transformation". In fact, some important concepts in Industry 4.0 include "networking", "value chains", "vertical and horizontal integration", and "coengineering / through engineering", which very well match the issues addressed for the Collaborative Networks.

\section{Final Remarks}

Looking at the future of the manufacturing industry, as a complex collaborative transformation system, requires understanding of the past. It is full recognized that technologies can quickly change the economic landscape of a country and the world. This occurred in the 18th Century, through the first Industrial Revolution and again in the beginning of 20th Century with the development of taylorism and the mass production paradigm. In the late 20th Century, the rapid development of consumer electronics was followed by the massification of personal computers and later the internet. Although these latter developments, they have already changed the lives and 
working habits of a generation. Countries willing and capable of taking advantage of these new technologies prosper, where others fall behind [12].

It used to take a very long 'time-to-market' for new research results and discoveries to be commercialized. However, nowadays this has changed radically between countries to bring new technologies and solution to market in a faster way, to gain a differentiation "advantage and establish a dominant market position in the following years. This was achieved by the US through the rapid commercialization of technologies such as semiconductors, computers, and the internet". Looking at the past, the history of industrialization shows us that from a relationship of personalization centered on the craftsman, it has evolved into a mass production environment where "power" has passed to the side of the producer and simultaneously all the productive activity is decoupled from consumers. In this evolutionary line, another relevant fact has to do with the growth of services weight in the economy and the consequent loss of importance in the society of the manufacturing activity. However, today we are seeing a real paradigm shift. The exponent of this change will materialize with the implantation of what is meant by "factory of the future", in the environment of what is understood to be the fourth industrial revolution. There will be, in this context, the active and collaborative participation of the consumer in the processes of creation and transformation processes. Increasingly, the transformation system will be full distributed, forming a true collaborative ecosystem, autonomous and adaptive in the processes of value creation.

Nowadays in manufacturing here are still many unresolved issues, uncertainties and challenges. In fact, European industry in particular has been facing substantial economic challenges stemming not only from the increased pace of technological development, the decline in the availability of natural resources, rising energy prices, but also the aging of the working class and, of course, the globalization of markets. It is therefore in this demanding and challenging context that Industry 4.0 promotes a vision in which developments in information technologies are expected to enable new forms of design and production. We will see an increasingly active consumer participation in the creation and production processes.

The "brand image" of this fourth industrial revolution is undoubtedly the consonance of internet technologies, namely with the massification of the "internet of things", with the exponential increase of computational capacity and in particular of the so-called "cloud computing". Therefore, a new generation of industrial systems based on innovative services will emerge whose functionalities reside in intelligent factories and machines, cyber-physical systems, natural man-machine integration, autonomy and adaptability, product and service systems, virtualization, augmented reality and the "cloud".

In particular. in the context of collaborative manufacturing and logistics, digital marketplace platforms have not yet moved completely from supporting simple collaboration approaches [15]. Indeed, the design, development, implementation and use of future Collaborative Transformation Systems require an ever-increasing knowledge on enabling technologies and business and operational practices. Moreover, the digital and networked world will surely trigger new business and operational practices in manufacturing. Therefore, this is relevant and current research issue to guarantee an effective and efficient performance. In this context, competitive 
and sustainable development is emerging as the core global strategic vision to be deployed so as to meet the economic, social, environmental and technological challenges that most societies are facing today and in particular in mature countries.

\section{Acknowledgements}

This work is part of the Project "TEC4Growth - Pervasive Intelligence, Enhancers and Proofs of Concept with Industrial Impact/NORTE-01-0145-FEDER-000020" is financed by the North Portugal Regional Operational Programme (NORTE 2020), under the PORTUGAL 2020 Partnership Agreement, and through the European Regional Development Fund (ERDF).

\section{References}

1. The Five Country Classifications, http://timmecarthy.com/the-five-country-classifications/

2. LINKS, P. Emerging trends in global advanced manufacturing. University of Cambridge (2013)

3. EFFRA. Factories of the Future - Multi-annual roadmap for the contractual PPP under Horizon 2020 (2013)

4. Azevedo, Américo, ed. Advances in sustainable and competitive manufacturing systems. Springer Science \& Business Media (2013)

5. Lu, Yan, Katherine C. Morris, and Simon Frechette: Current standards landscape for smart manufacturing systems. National Institute of Standards and Technology, NISTIR 8107: 22$28(2016)$

6. Schwab, K.: The global competitiveness report 2016-2017, ed. WE Forum (2016)

7. Schumacher, Andreas, Selim Erol, and Wilfried Sihn: A maturity model for assessing industry 4.0 readiness and maturity of manufacturing enterprises. In: Procedia CIRP 52: 161-166 (2016)

8. Ganzarain, Jaione, and Nekane Errasti: Three stage maturity model in SME's toward industry 4.0. Journal of Industrial Engineering and Management 9.5: 1119 (2016)

9. De Carolis, Anna, et al:: A maturity model for assessing the digital readiness of manufacturing companies. In: IFIP International Conference on Advances in Production Management Systems. Springer, Cham (2017)

10. Camarinha-Matos, Luis M., et al.: Collaborative networked organizations-Concepts and practice in manufacturing enterprises: Computers \& Industrial Engineering 57.1: 46-60 (2009)

11.Camarinha-Matos, Luis M., Rosanna Fornasiero, and Hamideh Afsarmanesh: Collaborative networks as a core enabler of industry 4.0. . In: Collaboration in a Data-Rich World, IFIP AICT 506, pp 3-17, Springer, Cham (2017)

12. Hauser, Hermann. The Current and Future Role of Technology and Innovation Centres in the UK: A Report. Department for Business Innovation and Skills (2010)

13. Appio, Francesco Paolo, et al.: Collaborative network of firms: antecedents and state-ofthe-art properties. International Journal of Production Research 55.7: 2121-2134 (2017)

14. Durugbo, Christopher: Collaborative networks: a systematic review and multi-level framework." International Journal of Production Research 54.12: 3749-3776 (2016)

15. Cisneros-Cabrera, Sonia, et al.: Digital Marketplaces for Industry 4.0: A Survey and Gap Analysis. Working Conference on Virtual Enterprises. Springer, Cham (2017) 